\title{
Acute Mountain Sickness - Experience on the Roof of Africa Expedition and Military Implications
}

\author{
Maj M J Roberts \\ MA, BM, BCh, DA, RAMC \\ Dept of Anaesthetics, Queen Elizabeth Military Hospital, Woolwich, London SE18 4QH
}

SUMMARY: Acute Mountain Sickness (AMS) is a potentially severe problem for military exercises and operations and may present in a variety of ways as was the case on the "Roof of Africa" Expedition 1990. Four cases are described and the pathophysiology of AMS is discussed.

Gradual acclimatization to increasing altitude will decrease the incidence of AMS, but pharmacological prophylaxis is recommended when time is short, acetazolamide being the drug of choice.

\section{Introduction}

Acute Mountain Sickness (AMS) affects those who ascend to high altitude without adequate acclimatization. The drop in barometric pressure with increasing altitude results in a fall in the partial pressure of Oxygen in the inspired air $\left(\mathrm{P}_{\mathrm{I}} \mathrm{O}_{2}\right)$ and hence reduced alveolar $\left(\mathrm{P}_{\mathrm{A}} \mathrm{O}_{2}\right)$ and arterial $\left(\mathrm{P}_{\mathrm{a}} \mathrm{O}_{2}\right)$ oxygen tension.

The alveolar oxygen tension depends not only on the level of inspired oxygen but also the degree of ventilation as demonstrated by the alveolar gas equation:

$$
\mathrm{P}_{\mathrm{A}} \mathrm{O}_{2}=\mathrm{P}_{\mathrm{I}} \mathrm{O}_{2}-\frac{\mathrm{P}_{\mathrm{A}} \mathrm{CO}_{2}}{\mathrm{R}}
$$

Where $\mathrm{P}_{\mathrm{A}} \mathrm{CO}_{2}$ is the alveolar carbon dioxide tension and $\mathrm{R}$ is the respiratory quotient. At 18,000 feet above sea level the $\mathrm{P}_{\mathrm{I}} \mathrm{O}_{2}$ is approximately $70 \mathrm{~mm} \mathrm{Hg}$ so that with a normal minute volume, a $\mathrm{P}_{\mathrm{A}} \mathrm{CO}_{2}$ of $40 \mathrm{mmHg}$ and a respiratory quotient of 0.8 the $\mathrm{P}_{\mathrm{A}} \mathrm{O}_{2}$ would be only $20 \mathrm{~mm}$ $\mathrm{Hg}$ as compared to $100 \mathrm{~mm} \mathrm{Hg}$ at sea level.

During exercise at altitude $\mathrm{P}_{\mathrm{a}} \mathrm{O}_{2}$ may not reach the level of $\mathrm{P}_{\mathrm{A}} \mathrm{O}_{2}$ due to the decreased gradient of oxygen tensions in the face of an increased pulmonary capillary velocity. The shape of the oxygen dissociation curve also decreases the rate of rise of $\mathrm{PO}_{2}$ in the pulmonary capillary at lower oxygen tensions (1). The result of these processes is therefore low arterial oxygen tension.

The response to this hypoxaemia is to increase ventilation and reduce the $\mathrm{P}_{\mathrm{A}} \mathrm{CO}_{2}$ and hence increase $\mathrm{P}_{\mathrm{A}} \mathrm{O}_{2}$. However, the rise in $\mathrm{Ph}$ and the hypocarbia would normally oppose the drive to hyperventilate. This problem is resolved in the process of acclimatization. Acclimatization involves firstly, a movement of bicarbonate out of CSF thereby allowing hyperventilation to take place without decreasing central stimulation by hydrogen ions, and secondly, by renal excretion of bicarbonate to compensate for the respiratory alkalosis brought on by the hyperventilation. This should take two or three days. Another aspect is the increase in 2.3 diphosphoglycerate which shifts the oxygen dissociation curve to the right facilitating off load- ing of oxygen in the tissues and acting against the left ward shift due to alkalosis and hypocarbia.

In 1990 the Roof of Africa Expedition was undertaken by the First Battalion Welsh Guards. Among its several objectives were seven mountains ranging from ten to twenty thousand feet above sea level (Table 1). The teams changed five times during the year except for a central team of five. Two of the groups attempted more than one mountain.

Table 1

\begin{tabular}{llc}
\hline Mountain & Country & Height in Metres \\
\hline Jebel Toubkal & Morocco & 4206 \\
Mount Cameroon & Cameroon & 4108 \\
Mount Stanley & Zaire & 5157 \\
Karisimbi Peak & Rwanda & 4548 \\
Mount Kenya & Kenya & 5246 \\
Kilimanjaro & Tanzania & 5951 \\
Mount Mulanje & Malawi & 3077 \\
\hline
\end{tabular}

The eighty two expedition members were not selected to have a very high level of physical fitness but they were required to be healthy and to have passed basic fitness tests at their parent units. There were men and women aged between eighteen and forty-two years and ranked from Private Soldier to Captain. Several branches of the Army were represented and personnel from the Royal Navy and Royal Air Force were also included. At the outset no plans were made to study AMS during the expedition but consideration was given to its management prior to departure. Two questions arose: How to treat it and how to prevent it.

The first was the simpler; descent is the definitive treatment to which most respond. In cases of pulmonary oedema, one of the most serious complications, diuretics might be used. Antiemetics and simple analgesics would also be needed. As for prevention, it was decided that the best option would be careful planned acclimatization on the mountains, ascending in easy stages.

Very few, if any, escaped the effects of mountain sickness with symptoms being more and more evident with 
increasing altitudes. The most common symptoms experienced are listed in Table 2 . If the anorexia and nausea was allowed to cause dehydration the feelings of general malaise were exacerbated. The following cases demonstrate the range of presentations possible in acute mountain sickness.

Table 2

\begin{tabular}{cl}
\hline Commonest Symptoms of AMS on R.A.O. Expedition \\
\hline Fatigue & Light Headedness \\
Anorexia & Parasthesia \\
Nausea & Malaise \\
Headache & Apprehension \\
Dyspnoea & Poor Concentration \\
\hline
\end{tabular}

\section{Case 1}

A Royal Electrical and Mechanical Engineer Corporal complained of shortness of breath and fatigue on reaching the summit of Mount Cameroon. He was coughing and producing specks of blood. Improvement occurred rapidly on descent and he felt well at the base camp. He was subsequently unable to reach the summit of Karisimbi due to nausea, vomiting and malaise.

\section{Case 2}

A very fit 18 year old guardsman, having not complained of any symptoms up to 15,500 feet on Mount Stanley, suddenly complained of a headache and lost consciousness within two minutes. Over the next thirty minutes he drifted in and out of consciousness while being slowly manhandled across and down a deep snowfield.

He was then evacuated to a hut at 14,700 feet by a difficult abseil between two other members of the team. His condition was complicated by hypothermia which rapidly developed once he stopped moving. Once warmed and dried he felt better, complaining only of fatigue and headache and with a hot meal and a nights sleep was able to descend off the mountain with minimal assistance.

\section{Case 3}

A twenty-eight year old Queen Alexandra Royal Army Nursing Corps Captain suffered increasing fatigue on the ascent to the summit of Kilimanjaro. She achieved the summit and descended to camp in the crater at 18,500 feet. During the night she experienced alarming paroxysmal, dyspnoea and orthopnoea. Descent was not practical that night but she improved rapidly the next morning with loss of altitude.

\section{Case 4}

A senior non-commissioned officer experienced nausea and repeated vomiting followed by a small haematemesis during the ascent on Kilimanjaro. He descended, recovered and next day was able to ascend slowly and achieved the summit.

\section{Discussion}

AMS causes unpleasant and inconvenient symptoms, aब well as potentially fatal complications. Symptoms are caused by hypoxia, alkalosis, an increase in cerebra blood flow, cerebral oedema and pulmonary oedema, the latter secondary to hypoxic pulmonary hypertension an increased pulmonary capillary permeability. The mortalite in cases of pulmonary oedema range from 4 to 27 depending on the speed of evacuation.

It has been shown that AMS is common above 2,05 metres and often severe enough to prompt self medicatio (2). Also a study amongst United States Marines corn్ firmed the occurrence of incapacitating symptoms in per-1 sonnel training at altitudes above $2,065 \mathrm{~m}$ resulting in pre sentation to medical officers (3). It is clear therefore that there are good medical and military reasons for minimis? ing the occurrence of AMS even at these intermediate altin tudes. Slow planned acclimatization is the method use most commonly among mountaineers to prevent AMS However there may be great variability in the time required for individuals to adequately acclimatize an $\$$ anecdotal evidence suggests that some find it virtualli impossible. Secondly slow ascent may not have a place i some military scenarios. Acetazolamide is the most widely used of the pharmacological interventions to $\mathrm{Bre}_{\mathrm{T}}$ vent AMS. A carbonic anhydrase antagonist, it decreas renal reabsorption of bicarbonate thus increasing the fofte of the renal contribution to acclimatization. It is likely 票迸 it also stimulates central chemoreceptors to increase the ventilation at a given $\mathrm{P}_{\mathrm{a}} \mathrm{CO}_{2}$ and opposing the brakeosom hyperventilation caused by the alkalosis. Improvement in the sleep disturbance caused by periodic breathing 商. occur due to an inhibition of the peripheral chemorecep tors response to hypoxia (4). One suggested regimen acetazolamide 250 milligrammes every 8 hours.

Dexamethasone 4 milligrammes 8 hourly has bee@ shown to be more effective than acetazolomide or placeb $\overrightarrow{\vec{\theta}}$ in reducing the symptoms of AMS (5). It may be that the reduces the large increase in the plasma levels of eicon soids (prostaglandins, thromboxanes and leukotrienes? which occurs on exposure to hypoxia in a time course consistent with development of AMS (6). The role of dex amethasone may be in subjects requiring rapid ascent bu with a guaranteed descent after a short period, and for the improvement of symptoms in an AMS casualty durin descent especially if his co-operation is required.

Nifedipine 20 milligrammes in a slow release prepara. tion every 8 hours has been investigated and shown ts prevent increases in pulmonary artery pressure and pre vent high altitude pulmonary oedema in subjects know@ to be susceptible (7). The place of Nifedipine in prophy laxis or treatment is unclear.

Although the Roof of Africa Expedition involved rel tively small numbers it was apparent that some individe als are more susceptible than others to AMS. It may bD that susceptible subjects can be identified prior to expd sure to altitude $(8,9)$. On this expedition the intention was 
to rely on acclimatization as the means of reducing or preventing AMS on the expedition. However, it was not in the event always practical to do so as thoroughly as it might have been wished. It is likely that these conditions would apply in 'out of area' operations at altitudes where speed of execution may be paramount and therefore a similar experience of AMS could be expected.

The problem for the military would appear to be twofold. Firstly, exercises, expeditions and operations at high altitudes can result in severe and potentially fatal cases of pulmonary and cerebral oedema. Secondly at intermediate and high altitude there can be sufficient incapacitation of individuals by relatively minor symptoms to decrease the efficiency of a unit and undermine the operation, particularly if key personnel are involved or if prolonged or difficult casualty evacuations are required.

Complete acclimatization is the ideal way of reducing the incidence of AMS but this is not practical when time is short. Therefore, pharmacological prophylaxsis should be considered for expeditions to high altitudes and for operational personnel at altitudes as low as 2000 metres. At the moment the drug of choice would be acetazolamide for prophylaxis but dexamethasone should be carried for emergency use. Furthermore, the identification of those personnel susceptible to high altitude pulmonary oedema may have a role prior to exposure to altitude.

\section{REFERENCES}

1. West J B. Respiratory Physiology - The Essentials 4th Ed Baltimore, William and Wilkins 1990.
2. Montgommery A B, Mills J, Luce J M. Incidence of Acute Mountain Sickness at Intermediate Altitude. JAMA 1989; 261(5): 732-4.

3. Pigman E C, Karakla D W. Acute Mountain Sickness at Intermediate Altitude: Military Mountainous Training. Am J Emerg Med 1990; 8(1): 7-10.

4. Bashir Y, Kann M, Stradling J R. The Effect of $\underset{\vec{D}}{\vec{D}}$ Acetazolamide on Hypercapnic and Eucapnic/Poik- $\bar{C}$ ilocapnic Hypoxic Ventilatory Responses in Normal Subjects. Pulm-Pharmacol 1990; 3(3): 151-40.

5. Ellsworth A J, Meyer E F, Larson E B. Acetazo- $\stackrel{\mathbb{Q}}{\Omega}$ lamide or Dexamethasone use Versus Placebo to Pre- ® vent Acute Mountain Sickness on Mount Rainer. West J Med 1991; 154(3): 289-93.

6. Richalet J P, Hornych A, Rathat C, et al. Plasma $\overrightarrow{\vec{\omega}}$ Prostaglandins, Leukotrienes and Thromboxane in $\stackrel{\sigma}{S}$ Acute High Altitude Hypoxia. Respir Physiol 1991; 85(2): 205-15.

7. Bartch P, Maggiorini, Ritter M, et al. Prevention of High Altitude Pulmonary Oedema by Nifedipine. N Engl J Med 1991; 325(18): 1306-7

8. Yagi H, Yamada H, Kobayashi T, Sekiguchi M. $\frac{\dot{\omega}}{\omega}$ Doppler Assessment of Pulmonary Hypertension Induced by Hypoxic Breathing in Subjects Susceptible to High Altitude Pulmonary Oedema. Am Ref Respir Dis 1990; 142(4): 796-801.

9. Kawashima A, Kubo K, Kobayashi T, Sekiguch M. Haemodynamic Responses to Acute Hypoxi® Hypobaria and Exercise in Subjects Susceptible High Altitude Pulmonary Oedema. J Appl Physig 1989; 67(5): 1982-9. 